\title{
Tradução e língua: visão de mundos, mundos de visões
}

\author{
Francisca Eugênia dos Santos ${ }^{1}$
}

Ana Laura dos Santos Marques ${ }^{2}$

Resumen: Este artículo pretende reflexionar acerca de los diferentes aspectos lingüísticos y socio-culturales que la práctica de la traducción abarca, la adquisición de la lengua extranjera y la identidad del traductor. Consideramos que aún persiste una mentalidad tradicionalmente formada en el interior de las carreras universitarias que proponen caminos unidisciplinarios. Esta práctica nos lleva a depararnos con dificultades metodológicas y didácticas en el momento de caracterizar situaciones comunicacionales complejas. Construir una identidad, una representatividad social del sujeto traductor a través de la lengua es la condición de siglos de estudios de la traducción.

Palavras-chave: Tradução, língua estrangeira, identidade, representação social

Resumo: Este artigo pretende refletir sobre os diferentes aspectos lingüísticos e sócio-culturais que abrange a prática da tradução, a aquisição da língua estrangeira e a identidade do tradutor. Consideramos que ainda persiste uma mentalidade tradicionalmente formada no interior dos cursos universitários que propõem caminhos unidisciplinares. Esta prática nos leva a depararnos com dificuldades metodologias e didáticas no momento de caracterizar situações comunicacionais complexas. Construir uma identidade, uma representatividade social do sujeito-tradutor através da língua, é a contradição desses séculos de estudo da tradução.

Palabras-clave: traducción, lengua extranjera, identidad, representación social

“A linguagem é um sistema de signos móveis e que, até certo ponto, podem ser trocados: uma palavra pode ser substituida por outra e cada frase pode ser dita (traduzida) por outra. Parodiando a Peirce poderia dizer que o significado de uma palavra é sempre outra palavra."

Octavio Paz - Literatura e literalidade

1 Departamento de Lingüística e Literatura, Facultad de Humanidades, Universidad de Santiago de Chile

2 Departamento de Lingüística e Literatura, Facultad de Humanidades, Universidad de Santiago de Chile 


\section{Introdução: a prática da tradução}

É indiscutível que a tradução é uma atividade complexa como a própria realidade da língua. Indiscutível também é a forma como se posiciona dentro das áreas do conhecimento: uma prática dentro de outras práticas.

Octávio Paz, assim como outros ensaístas e poetas dentro da nossa literatura, dedicaram-se à prática da tradução. Ou melhor, eram cotados pelas editoras, como o caso de Borges, por exemplo, para realizar a "perfeita" tradução de grandes clássicos da literatura e da poesia universal. Nós nos perguntamos quais eram as características que possuíam esses grandes escritores e poetas que mereciam este galardão "escolhido" para um trabalho complexo. Não é difícil que a nossa resposta recorra ao conhecimento cultural e à sensibilidade do escritor. O escritor é aquele capaz de representar em sua época os problemas e simbolismos do seu povo transmitindo através da sua narrativa, o discurso do seu cotidiano. Seriam essas as qualidades válidas no trabalho do tradutor? Sem dúvida são características e atributos que deveriam ter um tradutor na sua essência profissional, características estas que podemos aludir a situações profissionais as quais "ele/tradutor" como sujeito pertencente a um momento histórico deveria ter para dialogar com um determinado texto.

O texto é a realidade empírica do tradutor no seu intuito por encontrar as equivalências linguísticas da língua meta. Dessa forma, seu trabalho se estende por diferentes âmbitos do conhecimento e podemos declará-lo como um sujeito "muldimensional". Quando falamos de equivalências linguísticas, encontramo-nos com a etimologia de uma palavraequivalência - que representa "valores iguais". Discute-se, há muito, o que é a equivalência dentro da tradução, uma vez que encontrar valores equivalentes em línguas diferentes possibilitaria o que os teóricos assumem como "a impossibilidade da tradução".

Dentro dos estudos lingüísticos e tradutológicos é importante mencionar que uma das primeiras relações que deveria fazer o tradutor com o seu mundo real seria entendê-lo como um mundo de palavras, de expressões idiomáticas, de signos e de significados. Certamente, este é o principio da linguística que conforma um objeto tão complexo quanto o objeto da tradução.

Refletindo sobre o objeto da linguística, na luta diária por determinar nos sujeitos o caráter da língua e encontrar os fenômenos externos que influenciam na criação e formação de novas expressões, delimita-se a língua. Essa língua, desde os anos 1960, é a fonte dos pesquisadores que intervém em realidades culturais específicas. Esta língua varia e cria, materializando mundos a partir da palavra.

Se compreendermos a língua como produto do pensamento humano, criado por sujeitos sociais, recorremos a muitos dos estudos das ciências humanas, mas particularmente à linguística. Nesse momento, dadas as características da nossa reflexão, discutiremos a língua e o pensamento a partir da sua união e consequência, como dizia um dos seus fundadores: "supõe-se que as idéias são anteriores às palavras, (...) não nos dizem se o nome é de natureza vocal ou psíquica, (...) deixam supor que o laço que une um nome a uma coisa é uma operação simples" (Saussure 1999: 121). Essa operação simples à qual se referia Saussure completa-se na materialidade implícita da língua. Desde os primórdios da comunicação, cada cultura produziu os seus próprios símbolos e os seus próprios signos: "O signo linguístico une não uma coisa e um nome, mas um conceito e uma imagem acústica. Signo linguístico é precisamente uma entidade psíquica de duas faces, composto pelo conceito e pela imagem acústica..." Saussure (1999:124). Nesse caso, dependendo da entidade psíquica de duas ou mais faces dependerá o conceito criado. 
A tradução defendida por alguns teóricos como atividade linguística, argumento utilizado pela condição fundamental do "saber" uma língua estrangeira, transforma-se em uma dicotomia própria da atividade tradutória. Essa realidade dicotômica, a do tradutor, irá se transformar ou o levará a manter ou destruir a visão da sua realidade, quando se depare com outra realidade. Uma realidade mantida viva na comparação antropológica do sujeito/língua.

\section{Tradução e a aprendizagem da língua estrangeira}

Como o sujeito social se condiciona a aprender uma língua estrangeira? Para fins desse artigo, partiremos do princípio de que o aprendiz de uma língua tem como primeira meta comunicar-se eficazmente nessa língua. E antes, está disposto a fazê-lo, ainda que seu sucesso não dependa somente dessa autodeterminação. Tendo em mente esses dois fatores, o aprendiz certamente buscará um conhecimento da estrutura da língua, um conhecimento sócio-cultural dos contextos em que essa língua é e pode ser produzida e um conhecimento dos recursos que lhe possibilitem desenvolver-se numa interação nessa língua, mesmo com um domínio parcial de suas estruturas (léxico, sintaxe, semântica). Nesse sentido, é válida a definição de Selinker (1972) relacionada ao domínio parcial de uma língua (muitas vezes, mais amplo ou mais restrito e por tempo indefinido) - a interlíngua - que um aprendiz de língua estrangeira vivencia com relação ao seu objeto de estudo. Enquanto desenvolve sua interlíngua, tentará traspassar a ela estruturas e contextos, significados e experiências de sua língua materna ou de outras línguas previamente conhecidas. Sua língua materna (LM) será quase sempre o ponto inicial de aprendizagem de uma nova língua. A ela, recorrerá caso necessite desempenhar-se em situações imprevistas e, sendo esta língua fator de apoio, delimitará o grau de aceitação que o aprendiz terá da nova língua.

Ao pensarmos no indivíduo que aprende uma língua estrangeira (LE), detectamos duas visões sobre o mesmo processo, dicotômicas: a primeira é aquela na qual o sujeito admite-se como estrangeiro, usando uma língua que não é a sua e por isso mesmo "autorizado" por instâncias de aprendizagem (escola - instituto - professor) a cometer erros, já que não almeja o domínio desse mundo "estrangeiro". O domínio de sua língua materna lhe assegura a possibilidade de desempenhar-se dentro do conhecido e ver o mundo a partir dessa possibilidade. Já a segunda é aquela na qual o aprendiz tem como referência o falante nativo da língua em aprendizagem, por isso, almeja a excelência, a perfeição, sendo que a busca da melhoria de sua aprendizagem é constante. Suas expectativas em relação à sua aprendizagem são, portanto, altas. Não se trata de renegar sua língua materna, mas fazer da LE um caminho tão seguro quanto a primeira (ou às anteriores). $\mathrm{O}$ aprendiz entende que se pode expressar tudo por meio da associação de conceito/imagem acústica (Saussure, 1999), dessa forma, aceita a LE, com suas regras e valores.

Por outro lado, ao construir sua realidade nessa dinâmica dicotômica, o sujeito se aproxima de certa subalternidade, aceitando os valores e regras da outra língua e da outra realidade. Estaremos aqui no mundo da conduta lingüística, este ato em que o sujeito se prepara para interagir com o outro. A conduta lingüística cria as condicionantes e os estimulo sociais no processo de aprendizagem da língua. Claire Kramsch (1998:34-37) apresenta um exemplo típico de uma aula de língua estrangeira: um aluno pergunta ao professor como se diz um verbo em alemão. O professor lhe oferece três alternativas e acrescenta: a resposta correta depende do contexto. Quase sempre, essa resposta frustra as expectativas do aluno, que espera que a tradução da sua LM à LE seja exata, precisa e única. A autora afirma que "construir um ato de fala não significa apenas levar em conta 


\section{Conexão Letras}

fatores gramaticais e léxicos" (Kramsch (1998:37). Essa construção leva em conta decidir qual seria a forma adequada - através de uma avaliação que o falante faz de toda a situação de comunicação -, além de considerar as expectativas encontradas por parte do falante e do ouvinte envolvidos nessa situação (Kramsch, 1998:42).

É provável que, durante os primeiros estágios de aprendizagem de uma língua, o aprendiz se encontre escolhendo o que lhe parece "melhor" em cada situação de comunicação sem considerar realmente o que essa escolha requer do falante e de seu interlocutor. $\mathrm{O}$ estudante aprende que pedir desculpas/cumprimentar em LE corresponde a uma palavra ou expressão, mas deve entender também que ambas as situações não correspondem totalmente ao uso de uma expressão ou palavra que ele porventura faça em sua língua. Esse é um dos processos que exige uma técnica ou estratégia de aprendizagem desconectada da tradução, para que os condicionantes culturais da língua sejam internalizados como únicos.

Apesar dessa separação necessária entre aprendizagem de língua e tradução, é evidente que a tradução dependa da aprendizagem de uma LE: o conhecimento da língua alvo é fundamental para que na construção da mensagem de um texto conformem-se o conhecimento das estruturas (da LM e da LE) e o conhecimento cultural, num processo complexo de compreensão, redação e revisão.

Partindo do princípio de que a tradução não deveria estar em todo o processo de aprendizagem da língua, mas que ela depende do domínio das estruturas aprendidas, admitimos que seria necessário rever o significado da tradução como ato comunicativo que não se norteia apenas por parâmetros gramaticais e discursivos. Reduzi-la a um conjunto de técnicas pertencentes de modo exclusivo à linguística não nos parece adequado.

No âmbito do ato tradutório e da tradução como ciência, podemos ver esse mundo recortado pela língua materna e pela língua meta. Duas línguas, duas realidades, duas visões de mundo e um produto final: a visão do tradutor.

Quando a universalidade da cultura, seus padrões estéticos e morais foram considerados pelos antropólogos como presentes em todos os grupos humanos, passamos a comparar os aspectos lingüísticos, os mitos, a família, expressões artísticas como formas elementares do nosso "modo de fazer" as coisas (Lévi-Strauss, 1949). Um "modo de fazer" representativo da vida humana e dos sujeitos criadores dessas sociedades. Por esse motivo, a comunicação estabelecida entre estes sujeitos e a ordem das coisas criadas são vistas de diferentes perspectivas pelas ciências humanas. Cada qual estudará um objeto diferente desse sujeito criador.

Dessa forma, o objeto da linguística é estudado a partir de duas dimensões: o funcional e o formal. Essas duas dimensões se dividem na gramática e na pragmática. Consideradas dentro do pensamento daqueles que as defendem, mas muitas vezes difundidas de forma errônea, nem sempre são compreendidas dentro da realidade empírica traçada pelos estudos da língua. Segundo a apreciação de Wolfgang Klein (1992), essas dimensões dependem da classificação que tenha cada teórico. Funcionalistas ou estruturalistas e suas aplicações e interesses. Esses se adaptam a refinamentos de realidades e a interdependências, o que vai conformar o objeto de cada uma dessas correntes teóricas.

Ao pensar que a tradução depende do conhecimento de duas línguas em sua dimensão estrutural e representativa, podemos afirmar que "o segredo da língua estrangeira depende da descoberta do segredo da nossa própria língua" (P. Ricouer, 2005:66). Este mistério a ser desvendado se torna um desafio para o tradutor no contraste das duas línguas. Haverá então dentro das áreas do conhecimento uma ciência que trate do estudo de duas línguas?

Muitos pensadores, teóricos, filósofos interessaram-se pelo estudo da tradução, ou pela análise crítica da tradução como atividade filosófica, antropológica e histórica, 
o que nos leva a concluir que um tradutor passeia por diferentes lugares dentro desse amplo leque de informação. Porém, o seu conhecimento interno e a forma como domina língua estrangeira é a resposta à sua identidade linguística. Ou seja, a responsabilidade do tradutor depende das características socioculturais e lingüísticas apreendidas no processo de aquisição da língua estrangeira.

Por outro lado pensamos que a aquisição da língua estrangeira é uma etapa crucial na formação do tradutor, pois não podemos conceber sua existência sem essa habilidade e o conhecimento da outra língua. Nas aulas de língua, assim como nas aulas de tradução, os estudantes veem o mundo como um campo minado de palavras e léxicos. Consideramos que aprender e ensinar essa realidade linguístico-tradutora é percorrer um caminho de caráter multidisciplinar. Porém, se pensamos que a realidade da língua não necessariamente está composta por duas ou três realidades, senão por múltiplas reflexões em torno das leituras desse mundo multifacetado, chegamos a concluir que, antes de tudo, esses indivíduos aprendizes da língua e da tradução manifestaram, à medida do possível, uma desejada sensibilidade sócio-cultural em sua busca da realidade alheia. É por este motivo que muitos dos filósofos e filólogos do século XIX e XX construíram através da tradução sua linha de análise, desafiando a tradução e impossibilitando as equivalências entre as línguas. Pensando que "existem línguas que hospedam outras línguas" (P. Ricouer, 2005: 65), e que cada língua tem seu próprio segredo, parece-nos sensato que a transmissão do conhecimento em uma área como a tradução esteja orientada a ampliar o mundo das idéias e das reflexões em torno da língua e seus matizes. Como exemplo, utilizamos a tradução de um texto de veterinária. $\mathrm{O}$ tradutor além de dominar a língua meta precisa ter o conhecimento do texto, da terminologia, e a pesquisa temática aqui funciona como o ponto crucial do seu trabalho. Não é necessário ser um veterinário, mas o mecanismo de busca dessa documentação especializada torna seu trabalho complexo. Construir o ato tradutório depende de operações externas e internas que vão desde a leitura, a reflexão, a pesquisa para, finalmente, chegar à redação. Convoca-nos, então, na formação do tradutor mais que a prática e a execução de tarefas, abstrações e interpretações de mundos especializados que cruzam disciplinas e pensamentos. Para traduzir, além da habilidade lingüística, requerem-se:

“... múltiplas competências, sendo a principal, talvez, a que tem por base a consciência de que a produção tradutiva de um texto tem de ter em conta a sua função específica, a cultura receptora e a sua localização espaço-temporal em determinados contexto pragmáticos e sócio-culturais." (Figueiredo, 2007:102)

Traduzir não é somente verter um texto de uma língua a outra, mas sim transformálo em outro. Ou seja, é fazê-lo parecer ao original, de modo que possa ser entendido e compreendido pelo o leitor da língua meta. Essa transformação é feita através de significados, de vivências, de pensamentos e da essência do outro ser humano. Transformar significa: "converter uma coisa em outra."

\section{Identidade do tradutor}

Dessa forma, a construção da identidade tradutora com base em tão complexa estrutura parte de, por um lado, o conhecimento aprofundado da realidade em que está inserido o tradutor para que tenha uma visão ampla da sua língua materna, por outro, a utilização dessa mesma estrutura na construção de sua identidade na língua estrangeira.

O desafio recai na construção dessas duas identidades, em que uma não invalida a outra, ou seja, edificam-se, à medida que uma abre espaço a outra. $\mathrm{O}$ ato tradutório, no 
entanto, transforma-se na interação entre duas sociedades e, em outras oportunidades, entre as diversas sociedades que denotam encontros linguísticos e culturais nos quais se “determinam comportamentos e padrões de fronteiras limitadas" (Martins, 2004).

A identidade do tradutor é composta por experiências diárias que lhe dão possibilidades de determinar através dos textos escritos a história e o tempo do outro. Uma dinâmica constante que depende de sua consciência, da sua conduta e da sua atitude como sujeito social dentro de um processo comprometedor e único. Nesse processo de identidade, participam o leitor, que é a meta desafiante, e o texto. Um conjunto de elementos que compõem a sua realidade e interferem na sua leitura de mundo. Nesse momento de construção de sentido de mundo, o tradutor tem que considerar que o texto é o autor, e os leitores são sua figura. Uma figura construída entre a idéia do autor e como chegar aos leitores do texto traduzido. Nesse caminho de auto-correção constante, o tradutor se vê envolvido em uma executiva tarefa: a de determinar quais são os caminhos a seguir que independem das técnicas aprendidas e da habilidade linguística adquirida. No ato tradutório, o tradutor está em uma situação concreta: ele diante do texto.

A leitura que o tradutor faz do texto é um momento único e é através dela que teremos o resultado da tradução. Esse resultado é controlado por um ato de interpretação e compromisso do leitor/tradutor, sujeito social que conhece seu papel político nessa sociedade da qual faz parte. A tradução é um compromisso social, se o tradutor transcende a dimensão do texto e considera que os leitores aos quais o texto está destinado estão junto a ele no momento desvendar o mistério do texto. Assim sendo, quando nos referimos às estratégias da tradução, às metodologias de pesquisa na área de tradução, ou mesmo às estruturas linguísticas determinadas, estamos nos referindo a um mundo que se define a partir de um conhecimento que cada tradutor traz do seu próprio mundo. São tantas situações textuais que um tradutor pode viver que está dentro dele esse repertório de decisões. E, dessa forma, como não mencionar Ladmiral (1979:203-204):

\footnotetext{
"Não é possível deduzir da teoria lingüística, nem sequer da teoria semiótica, "écnicas de tradução" que possam ser "aplicadas" de modo linear: a tradução não é uma prática, que tem a sua ordem específica; como tal, ela define-se por oposição ao discurso da teoria e ao fantasma de pretensas técnicas. Tendo em conta o hiato existente entre teoria e prática [...] que convém não perder de vista, o único benefício que se tem o direito de esperar de uma teoria da tradução, ou tradutologia, consiste em clarificar e em classificar [...] as de tradução, em conceituá-las para articular uma ógica da decisão".
}

Esta lógica da tradução é dada pelas visões de mundo do tradutor, mas acima de tudo, pelo mundo criado e recriado todos os dias. Essa realidade própria do tradutor, transformada através de metáforas políticas, sociais e lingüísticas, leva-o a decisões certeiras e inteligentes.

\section{Considerações finais: superando as convenções da língua}

A tradução é sem duvida um fenômeno comunicacional, resultado de mudanças tecnológicas, econômicas, sociais, culturais que envolvem a língua e suas diferentes vertentes, por isso, ao longo da história da humanidade tem provocado tantas tensões e chamado a atenção de tantos pensadores, filólogos e teóricos. Os fenômenos linguísticos, por sua vez, abrem-se em diferentes direções nessa reflexão interdisciplinar dentro das 
comunidades humanas, manifestando sentimentos, verdades, falsidades e, sobretudo o "cosmos" com que toda comunidade se constitui e se constrói. Considerando esse cenário comunicativo com o qual o tradutor deve trabalhar e que, ao mesmo tempo, é também sua ferramenta de trabalho - a língua como instrumento para uma boa tradução - propomos uma aprendizagem de língua diferencial para esse grupo. Além de aprender regras e estruturas, um tradutor requer da língua a expressão e compreensão máxima da interação entre usuários, em todos os âmbitos do viver e do saber.

$\mathrm{O}$ ato de tradutório é esta aventura onírica em que os povos seduzem, reconhecem e intercambiam através do tradutor. Pensamos na possibilidade de poder localizar o tradutor nas fronteiras semiológicas que possam simbolizar esse homem pluridimensional retratado através da língua. A tradução é a influência mútua através de grupos sociais, que são orientados por padrões de comportamento ditados por valores culturais-morais. Sendo assim, a tradução tem um papel social com um objeto que supera os acordos e as convenções que consagram a língua. Queremos enfatizar que a construção do sujeito-tradutor e sua visão multifacética na construção de sua identidade e na consagração final da outra língua é, sem dúvida, a fórmula do seu sucesso.

\section{Referências}

FIGUEIREDO, Vivina Almeida Carreira de Campos. A dimensão pragmática da tradução no ensino-aprendizagem da língua estrangeira especializada. Disponível em: http://sare.unianhanguera.edu.br/index.php/rtcom/article/view/140/139 . Acesso em 26 de maio de 2010.

FUSARO, C.F. Márcia. A tradução/interpretação e a transmissão do conhecimento. Disponível em: http://portal.uninove.br/marketing/cope/pdfs_revistas/dialogia/dialogia v2/dialogv2_marciafusaro.pdf

KLEIN, Wolfgang. Was kann sich die Übersetzungswissenschaft von der Linguistikerwarten? Apud: Emmel, Ina. Lingüística e Ciência da tradução: existe alguma relação? Disponível em: http://www.periodicos.ufsc.br/index.php/traducao/ article/viewFile/5184/4610. Acesso em 26 de maio de 2010.

KRAMSCH, Claire. Context and culture in language teaching. Oxford, Oxford University Press, 1998.

LADMIRAL, J. R. Traduzir: Teoremas para a tradução. Tradução de Cascais Franco. Lisboa, Publicações Europa-América, 1979.

LÉVI-STRAUSS, Claude. Estruturas elementares do parentesco. São Paulo, Editora Vozes/EDUSP, 1976.

MARTINS, Resende Aldrey. Paradigmas do ato tradutório. In: Transcriaçoes. Teoria e prática. Porto Alegre, Editora Evangrad, 2004.

PAGANO, Adriana. Competência em tradução. In: Cognição e discurso. Belo Horizonte, Editora UFMG, 2005.

RICOEUR, Paul. Sobre la traducción. Buenos Aires, Paidós, 2005.

SAUSSURE, F. Curso de Lingüística General. Buenos Aires, Editora Losada, 1999.

SELINKER, L. Interlanguage. IRAL, 10, (3), 1972. p. 209-231.

STEINER, George. Depois de Babel - Aspectos da Linguagem e Tradução. Lisboa, Editora Relógio D’Agua, 2003. 